\title{
CULPA E ABANDONO NA OBRA O PROCESSO DE KAFKA
}

\section{Guilherme de Oliveira Feldens ${ }^{1}$}

\begin{abstract}
RESUMO:
O presente artigo visa apresentar a importância das ideias de Kafka para questionar questões fundamentais no Direito e na Ciência Política como justiça, poder, legitimidade e direitos individuais. Ao final, procura-se demonstrar que o deslocamento, o abandono e a culpa de seus personagens continuam impulsionando pareceres críticos da política atual.
\end{abstract}

PALAVRAS-CHAVE: Justiça; Direito; Liberdade.

\section{Introdução}

Walter Benjamin, em uma de suas teses sobre a história, procurou construir uma história universal a partir do lado dos esquecidos da história (Benjamin, 1987, p. 225). Sua estratégia se configurou na denúncia de fragilidades e contradições no discurso dominante (Mate, 2005, p. 96), visando apresentar de maneira clara a opressão presente no discurso político da Modernidade.

A obra de Kafka, melhor que qualquer outra, cumpriu as propostas de Benjamin através da denúncia da opressão e submissão imposta pela racionalidade moderna. As sensações causadas pelas obras de Kafka não se limitam ao estranhamento do indivíduo diante dos procedimentos inerentes ao mundo administrado, mas convidam o leitor a questionar todos os princípios e valores presentes na tradição do Estado de Direito. O texto de $O$ processo, por exemplo, apresenta diversos momentos nos quais, de maneira genial, o autor expõe o primado real da segurança sobre a liberdade, próprio do liberalismo, dissimulado sob uma retórica de liberdade, que perde toda a credibilidade em momentos de crise, quando aparece de maneira direta a violência do Estado.

\footnotetext{
${ }^{1}$ Professor de Ciência Política e Teoria Geral do Estado, no Cesuca, Mestre em Direito, Doutorando em Filosofia. 


\section{Direito, Poder e Violência em $O$ processo.}

O romance $O$ processo trata da história de um homem que, ao acordar numa certa manhã, é surpreendido pela presença de autoridades que, por um motivo que ele não conhece, em razão de uma lei a qual ele não tem acesso, o notificam por um crime e uma acusação desconhecida. A partir disso, durante toda a obra, Kafka descreve a redução do indivíduo diante da organização e da burocracia do Estado. Os ambientes públicos, as salas de autoridades e os fóruns são apresentados como espaços claustrofóbicos, gerando mal-estar ao personagem principal (Joseph K.). Kafka descreve também a sala de sessões do tribunal como um local de pequena altura, na qual os indivíduos que a acessem tenham de se curvar diante do poder. Além disso, a sala do tribunal é circulada por diversas galerias, um verdadeiro labirinto, que simboliza as amarras que prendem o indivíduo ante o poder do Estado ${ }^{2}$.

A história contada em $O$ processo pode ser lida em conjunto com a oitava tese de Benjamin, segundo a qual "fascismo" e "progresso" não podem ser interpretados como opostos $^{3}$. Dessa maneira, pode-se chegar à conclusão de que o progresso e o desenvolvimento racional e institucional, ao contrário, são os melhores instrumentos para o aparelhamento da opressão e da redução do homem a mero cálculo de "bem-estar geral". Kafka não se sente atraído por expressões como "progresso" e "evolução", pois essas ideias criam a ilusão de que a imaturidade humana foi completamente superada, como acreditavam os pensadores iluministas. Na sua leitura, sua época pode ser entendida como um momento no qual o indivíduo sofre total dominação por um conjunto de sistemas políticos e instituições sociais.

Nessa perspectiva, seu pensamento critica ideologias e modelos que produzem liberdade, mas a submete a todos os tipos de controles, caracterizando-a como necessária, mas também perigosa. Assim, cria-se um sistema de equilíbrio entre liberdade e segurança,

\footnotetext{
${ }^{2}$ Em seu conto $A$ construção, Kafka conta a história de um ser que, para desfrutar plenamente de sua liberdade, busca construir um ambiente seguro capaz de protegê-lo de qualquer ameaça eventual da floresta. Porém, a própria construção acaba se tornando uma prisão da qual ele não pode mais escapar.

3 “'A tradição dos oprimidos nos ensina que o 'Estado de exceção' em que vivemos é na verdade a regra geral. Precisamos construir um conceito de história que corresponda a essa verdade. Nesse momento, percebemos que nossa tarefa é originar um verdadeiro estado de exceção; com isso, nossa posição ficará mais forte na luta contra o fascismo. Este se beneficia da circunstância de que seus adversários o enfrentam em nome do progreso, considerado como uma norma histórica. $\mathrm{O}$ assombro com o fato de que os episódios que vivemos no século $\mathrm{XX}$ 'ainda' sejam possíveis, não é um assombro filosófico. Ele não gera nenhum conhecimento, a não ser o conhecimento de que a concepção de história da qual emana semelhante assombro é insustentável" (Benjamin, 1987, p. 226).
} 
ocasionando o surgimento das instituições e técnicas disciplinadoras ${ }^{4}$. A vida humana acaba se incorporando às estratégias do poder, e o que seria uma teoria de garantia de exercício da liberdade torna-se uma rede que amarra o homem moderno dentro da segurança da lei (Mate, 2005, p. 107).

A obra de Kafka evidencia que o ser humano se encontra submetido completamente à legislação e ao poder do Estado. Os indivíduos são reduzidos a um número, a uma generalização, ficando objetivado conforme os fins instrumentais das regras de mercado (Ruiz, 2007, p. 270). A racionalidade instrumental, instrumento do modelo social hegemônico, passa a invadir os diversos âmbitos da existência humana. Quando se rompem as barreiras entre o público e o privado, como no momento em que os servidores públicos notificam K. dentro de seu quarto, o homem fica reduzido irreversivelmente diante do poder do Estado, tornando-se objeto de decisão do soberano (Mate, 2005, p. 87). Obedecendo a esses mecanismos, a dominação e a consequente exclusão de uma parcela de indivíduos, torna-se algo natural.

Segundo Reyes Mate, a Declaração dos Direitos do Homem e do Cidadão de 1789 apresenta uma ambiguidade que pode ser analisada em conjunto com esta perspectiva kafkiana. Para o autor (Mate, 2005, p. 100)

Não é o mesmo dizer que se tem todos os direitos humanos por ser homem e que se
é cidadão, isto é, nascido num território. Isso encontramos nessa declaração
fundante, posto que, no artigo primeiro declara-se que 'os homens nascem e
permanecem livres e iguais em direitos', enquanto no artigo seguinte especifica-se
que o 'objetivo de toda associação política é a conservação dos direitos naturais e
imprescindíveis do homem', quer dizer, os direitos naturais não vão pelo livre
nascer, não dependem do ADN, mas do reconhecimento do Estado-nação, isto é, de
sua condição de cidadão.

Assim, para o indivíduo ter seus direitos garantidos é necessário, acima de tudo, a cidadania, o "pertencer" a algum Estado, ou seja, a condição de liberdade acaba sendo o próprio cárcere kafkaniano do homem. No momento que o Estado é o elemento essencial de conservação da liberdade, o homem fica reduzido diante de seu poder ${ }^{5}$. Conclui-se, portanto,

\footnotetext{
4 “O momento em que se percebeu ser, segundo a economia do poder, mais eficaz e mais rentável vigiar que punir. Este momento corresponde à formação, ao mesmo tempo rápida e lenta, no século XVIII e no fim do século XIX, de um novo tipo de exercício do poder... Mas quando penso na mecânica do poder, penso em sua forma capilar de existir, no ponto em que o poder encontra o nível dos indivíduos, atinge seus corpos, vem se inserir em seus gestos, suas atividades, seus discursos, sua aprendizagem, sua vida cotidiana" (Focault, 1999, p. 131).

${ }^{5}$ Conforme Reyes Mate (2005, p. 101), "para haver direitos terão que existir documentos, e esses deverão ser do Estado. $\mathrm{O}$ sujeito real dos direitos humanos é o cidadão, não o ser humano que é elevado pela nação à categoria
} 
que não existe um momento de cultura que se conquista sem gerar barbárie ${ }^{6}$, e que, na política moderna, não há democracia liberal que não comporte uma redução dos homens a pura vida nua.

\section{O Indivíduo diante da lei}

No capítulo intitulado "Na Catedral”, Joseph. K. recebe, como encargo de seu emprego, a função de conduzir um cidadão italiano que visitava a cidade pela primeira vez. Então, um desencontro coloca o personagem principal em uma catedral, na qual um sacerdote está prestes a começar seu sermão. Surpreendentemente, o sacerdote se dirige a Joseph K. dizendo que seu processo caminha para a condenação e que ele é culpado. Joseph K. fica confuso diante das afirmações do sacerdote e pede ajuda para se livrar do processo. Porém, o sacerdote reafirma que K. não compreende bem a situação e narra a parábola "Diante da lei" :

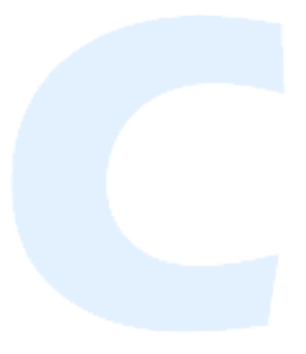

Diante da lei está postado um guarda. Até ele chega um homem do campo que lhe pede que o deixe entrar na lei. Mas o sentinela lhe diz que nesse momento não é permitido entrar. O homem reflete e depois pergunta se mais tarde lhe será permitido entrar. "É possível", diz o guarda, "mas agora não." A grande porta que dá para a lei está aberta de para em par como sempre, e o guarda se põe de lado; então o homem, inclinando-se para diante, olha para o interior através da porta. Quando o guarda percebe isso desata a rir e diz. "Se tanto te atrai entrar procura fazê-lo não obstante a minha proibição. Mas guarda bem isto: eu sou poderoso e

de sujeito de direitos. Esse ponto soberanista da nação não se vê em períodos normais nos quais nascimento e cidadania se confundem porque existe ajuste entre os nascimentos e a nação. Mas, o que acontece quando nesse território existem muitos não nascidos no mesmo ou quando alguns que ali nasceram são considerados como minoria étnica indesejável? Ora, nascimento e cidadania se separam e tudo fica reduzido ao nascimento: a maioria dominante invocará o sangue para desfazer-se daqueles que têm outro sangue e desta forma, todos, os expulsos e eles mesmos, permanecem assinalados pela categoria da vida natural".

${ }^{6}$ Conforme mostrado na tese VII sobre o conceito de história: "Fustel de Coulanges recomenda ao historiador interessado em ressucitar uma época que se esqueça tudo o que sabe sobre fases posteriores da história. Impossível caracterizar melhor o método com o qual rompeu com o materialismo histórico. Esse método é o da empatia. Sua origem é a inércia do coração, a acedia, que desespera de apropiar-se da verdadeira imagem histórica, em seu relampejar fugaz. Para os teóricos medievais, a acedia era o primeiro fundamento da tristeza. Flaubert, que a conhecia, escreveu: 'Peu de gens devineront combien il a fallu être triste pour ressusciter Carthage'. A natureza dessa tristeza se tornará mais clara se nos perguntarmos com quem o investigador historicista estabelece uma relação de empatia. A resposta é inequívoca: com o vencedor. Ora, os que num momento dado dominam são os herdeiros de todos os que venceram antes. A empatia com o vencedor beneficia sempre, portanto, esses dominadores. Isso diz tudo para o materialista histórico. Todos os que até hoje venceram participam do cortejo triunfal, em que os dominadores de hoje espezinham os corpos dos que estão prostrados no chão. Os despojos são carregados no cortejo, como de praxe. Esses despojos são o que chamamos de bens culturais. O materialista histórico os contempla com distanciamento. Pois todos os bens culturais que ele vê têm uma origem sobre a qual ele não pode refletir sem horror. Devem sua existência não somente ao esforço dos grandes gênios que os criaram, como a corvéia anônima dos seus contemporâneos. Nunca houve um monumento de cultura que não fosse também um monumento de barbárie. E, assim como a cultura não é isenta de barbárie, não o é tampouco, o processo de transmissão da cultura. Por isso, na medida do possível, o materialista histórico se desvia dela. Considera a sua tarefa escovar a história a contrapelo" (Benjamin, 1987, p. 225). 
contudo não sou mais do que o guarda mais inferior; em cada uma das salas existem outros sentinelas, um mais poderoso do que o outro. Eu não posso suportar já sequer o olhar do terceiro." O camponês não esperara tais dificuldades; parece-lhe que a lei tem de ser acessível sempre a todos, mas agora que examina com maior atenção o guarda, envolto em seu abrigo de peles, que tem grande nariz pontiagudo e barba longa, delgada e negra à moda dos tártaros, decide que é melhor esperar até que lhe dêem permissão para entrar. O guarda dá-lhe então um escabelo e o faz sentar-se a um lado, frente à porta. Ali passa o homem, sentado, dias e anos. Faz infinitas tentativas para entrar na lei e cansa o sentinela com suas súplicas. O sentinela às vezes o submete a pequenos interrogatórios, perguntando-lhe por sua pátria e por muitas outras coisas, mas no fundo não lhe interessam especialmente as respostas. Pergunta como o faria um grande senhor; e sempre termina por manifestar-lhe que ainda não pode entrar. O homem, que para realizar aquela viagem teve de se abastecer de muitas coisas, emprega tudo, por mais valioso que seja, para subornar o porteiro. Este aceita tudo, mas diz: "Aceito-o para que não julgues que te descuidastes de alguma coisa." Durante muitos anos aquele homem não afasta os seus olhos do sentinela. Esquece-se dos outros sentinelas e chega a parecer-lhe que este primeiro é o único obstáculo que lhe impede entrar na lei. Nos primeiros anos maldiz a gritos sua funesta sorte, mas depois, quando se torna velho, limita-se a grunhir entre dentes. E como nos longos anos que passou estudando o sentinela, chega a conhecer também as pulgas de seu abrigo de pele, tornado outra vez à infância, roga até a essas pulgas para que o auxiliem a quebrar a resistência do guarda. Por fim vê que a luz que seus olhos percebem é mais fraca e não consegue distinguir se realmente se fez noite ao redor dele ou se simplesmente são os olhos que o enganam. Mas agora, em meio à trevas, percebe um raio de luz inestinguível através da porta. Resta-lhe pouca vida. Antes de morrer concentram-se em sua mente todas as lembranças e pensamentos daquele tempo em uma pergunta que até esse momento não tinha ainda formulado ao sentinela. Como seu corpo já rígido não se pode mover, faz um sinal ao guarda para que se aproxime. Este precisa inclinar-se pois a diferença de dimensões entre um e outro chegou a fazer-se muito grande em virtude do empequenecimento do homem. "Que é o que ainda queres saber?", pergunta o sentinela. "És incontestável" "Dize-me”, diz o homem, "se todos desejam entrar na lei, como se explica que em tantos anos ninguém, além de mim, tenha pretendido fazê-lo?" O guarda percebe que o homem está já às portas da morte, de modo que para alcançar o seu ouvido moribundo ruge sobre ele: "Ninguém senão tu podia entrar aqui, pois esta entrada estava destinada apenas para ti. Agora eu me vou e a fecho (Kafka, 2001, p. 239-241)

A presente parábola de kakfa, narrada pelo sacerdote a Joseph K., surpreende o leitor ao fazer crer em seu princípio que o guardião era o obstáculo essencial e intransponível para que o camponês tivesse acesso a lei, pois em seu desfecho, revela que o guardião não estava ali para impedir o camponês de ingressar na lei. O principal obstáculo para o camponês era ele próprio, ao "pedir permissão" para acessar algo que estava, conforme dito pelo guardião, destinado somente a ele. Essa situação indica uma desconfiança interna do próprio camponês, um julgamento de indignidade, de culpa diante da lei, mesmo que ela não seja mais do que uma criação da própria humanidade. O camponês, diante dessa culpa, se coloca diante da lei como indigno dela.

Esse conto, além de retratar perfeitamente a situação do personagem principal de $O$ processo, que a essa altura já começava a questionar internamente a própria inocência ante 
uma acusação que sequer existe, abre um amplo campo de interpretação para questões referentes ao Direito e à justiça. Em primeiro lugar, é significativa a questão de o camponês estar em frente à lei, projetando sua situação e buscando alcançá-la, enquanto que o guardião, responsável por ela, se encontra voltado em sentido contrário a ela, ignorando-a.

Além disso, se a lei está "lá dentro", o camponês está fora dela ${ }^{7}$. O indivíduo, para Kafka, está abandonado ante uma lei que está em vigor, e cujo conteúdo escapa ao alcance do homem simples (Mate, 2005, p. 03). Uma lei que nunca muda, pois enquanto o camponês envelheceu no decorrer do conto, o guardião permaneceu igual. Esse fato remonta a questão levantada por Benjamin, para quem legislar, nos primórdios, significava um privilégio de reis e poderosos: "e assim será, mutatis mutandis, enquanto existir o Direito (Benjamin, 1987, p. 172). O sentimento de culpa demonstrado por Joseph K. e pelo camponês reforçam essa situação de impossibilidade de relação entre a lei e o homem comum, que a enxerga como um privilégio de determinadas pessoas e não se sente digno dela.

Por conta da análise dessa perspectiva, percebe-se, como traço característico dos textos de Kafka, a completa ausência de preocupação da ordem racional com a realidade individual do homem, tratando Joseph K. e o camponês como meros objetos da "justiça", não havendo qualquer traço de preocupação com injustiças. A restauração de qualquer injustiça torna-se efeito secundário da preservação da ordem e da segurança, quando a resposta correta, seria estabelecer uma forma de justiça capaz de resgatar a condição individual em uma relação de responsabilidade. $\mathrm{O}$ caráter fundamental dessa resposta seria fugir das abstrações modernas e reconhecer e reparar a alteridade sofrida dos oprimidos, para que seja possível responder aos casos concretos de sofrimento com responsabilidade ética. Essa atenção ao "fracassado", ao "homem comum", ao "camponês", prestada por Kafka, é profundamente inquietante e subversiva, tanto do ponto de vista epistemológico como político, porque questiona a autoridade do fático, trabalhando com as possibilidades, com o vazio.

A parábola analisada serve, acima de tudo, para denunciar a situação política da modernidade. Ao tratar o homem como se fosse culpável pelo fato de ter unicamente nascido, Kafka "está apenas descrevendo miticamente uma situação que o homem moderno está vivendo em tempos não mais míticos, porém modernos" (Mate, 2005, p. 103). E, isso não

\footnotetext{
${ }^{7}$ Conforme o colocado por Hannah Arendt (1987, p. 129), “a calamidade dos fora da lei não estriba em que se encontrem privados da vida, da liberdade e da prossecução da felicidade ou da igualdade diante da lei [...] mas que já não pertencem à comunidade alguma. Sua condição não é a de não serem iguais perante a lei, mas de que não existe lei alguma para eles. Não é que sejam oprimidos, mas que ninguém deseja sequer oprimi-los".
} 
porque o homem seja culpado, mas porque o poder e a política moderna criaram um mundo no qual o homem é tratado como se fosse culpável.

\section{Conclusão}

Conforme o demonstrado, Franz Kafka, através das ideias e fundamentos apresentados em sua obra, estabeleceu novas possibilidades relativas às concepções políticas e jurídicas presentes em seu contexto. Apesar de ainda, em certos aspetos, continuar vinculado a realidade que o cercava, Kafka, ao dar voz a personagens oprimidos, apresenta aspectos capazes de possibilitar uma crítica e reinterpretação da história a partir do ponto de vista daqueles que foram e continuam sendo vítimas de abusos, desrespeitos e políticas públicas desiguais que encontram suas raízes nos acontecimentos descritos pelo autor.

A obra de Kafka nos convida a repensar a política ao evidenciar, de maneira inteligente, que dificilmente será possível superar a violência política e caminhar rumo a uma sociedade justa se não acabar com formas e ideologias jurídicas que dissolvem a individualidade em um sistema idealizado.

\section{REFERÊNCIAS}

AGAMBEN, George. Homo sacer: o poder soberano e a vida nua. Belo Horizonte: UFMG, 2002.

ARENDT, Hannah. Origens do totalitarismo. São Paulo: Companhia das Letras, 1989.

BENJAMIN, Walter. "Sobre o conceito de história". In: Obras escolhidas. Magia e técnica, arte e política. Ensaios sobre literatura e história da cultura. São Paulo: Brasiliense, 1987.

FOCAULT, Michel. Microfísica do poder. Rio de Janeiro: Nau, 1999. 
KAFKA, Franz. O processo. SP: Martin Claret, 2001.

MATE, Reyes. Memórias de Auschwitz. São Leopoldo: Nova Harmonia, 2005. . Medianoche em la historia. Madri: Trota, 2006. 